\title{
Planning for Leisure, Sport, Tourism and the Arts: Goals and Rationales ${ }^{1}$
}

\author{
A. J. Veal* \\ School of Leisure, Sport and Tourism \\ University of Technology, Sydney
}

Published in World Leisure Journal, 53(2), 119-38, 2011.

\begin{abstract}
On the basis of a review of some 80 sets of official, professional and academic Englishlanguage guidelines, this paper evaluates eight rationales, goals and associated planning approaches for planning for leisure, sport, tourism and the arts: 1. Meeting standards; 2. Providing opportunity; 3. Managing (natural/heritage) resources; 4. Meeting demand; 5. Satisfying stakeholder groups; 6. Meeting needs; 7. Meeting participation targets; and 8. Providing (net) benefits. A number of the approaches are found to suffer from limitations which are generally overlooked by the guidelines reviewed. While guidelines are often strong in providing advice on data collection, they are invariably weak in regard to data analysis and the relationships between goal setting, data analysis and policy formation. A single solution to the difficulties identified is not offered, but it is concluded that a yet to be developed demand/ participation/benefits-based approach to planning would offer a way forward.
\end{abstract}

Keywords: leisure, sport, tourism, arts, cultural, planning, policy

\section{Introduction}

Planning for the future is a generic process involved in many spheres of human activity, including the provision of leisure services. Typically, particular areas of professional activity have their own specialised approaches to planning, and leisure planning is no exception. A recent review revealed the existence of some 80 sets of planning guidelines published over the last 45 years from a number of countries and covering leisure/recreation generally, outdoor recreation, sport, tourism and the arts, singly or in various combinations (Veal, 2011a). In this paper, except when specific points are made about individual sectors, the word leisure will be used to refer to all these sectors collectively. And when the term 'facilities' is used it is assumed to apply to 'services', although most of the latter are accommodated in the former. A feature of the review was the wide variety of planning approaches revealed, with differing implicit or explicit rationales and goals. The variety of approaches reflects, in part, the evolution of the public leisure services sector over time and can be seen as healthy, but it can also be confusing to the potential user. Furthermore, many of the guidelines fail to define concepts clearly, and lack detail and clarity in regard to methodology and rationale.

The World Leisure Journal seeks to address a readership which includes policy-makers and managers as well as researchers, scholars and educators. This paper is located in the space perhaps the yawning gap - between the two groups. The paper is not based on an analysis of

\footnotetext{
${ }^{1}$ The author contributed an article on this topic to the World Leisure Journal in 1984 (Veal, 1984). It consisted of a list of planning techniques but without consideration of overall approaches. The current review is a development of that article, and later versions of it.

*Email: Tony.Veal@uts.edu.au
} 
actual examples of leisure planning and their implementation, but on the guidelines for such planning produced by government departments and agencies, professional and industry organisations, consultants and academics. Such guidelines are intended to influence the ways in which leisure planning is undertaken and how substantial public resources are allocated. The aim of the paper is to draw attention to the inconsistencies and weaknesses of past and current guidelines. A complete remedy to the problems identified is not presented, but some suggested directions are offered. An historical approach is adopted since part of the story is the effort by a number of contributors in the field to develop replacements for one popular approach, the use of fixed provision standards, an effort which began in the 1960s (Sports Council, 1968) and is still ongoing. The introduction of State-wide Comprehensive Outdoor Recreation Plans in the United States in 1965 (National Parks Service, 1965) marked the start of widespread formal leisure planning activity in the Western world, so this date is taken as the start of the study period, which extends up to the present day.

Eight main rationales/approaches were identified in the review and discussion of these constitutes the bulk of this paper. Before proceeding to that discussion, a brief summary of the scope of the review and some general results from it are presented.

-Table 1 about here

\section{Guidelines for planning in the leisure, sport, tourism and arts sectors}

Table 1 provides details of the 80 sets of guidelines included in the review. The key criterion for selection of documents was that they should seek to offer guidance for the preparation of plans for leisure/recreation, sport, tourism or the arts/culture. For practical reasons, only documents in English were included. Literature which provides critical, theoretical analysis of planning, while invariably valid in its own right, was not included if it did not also include a 'how-to-do-it' component. The planning activity involved typically takes place at the single local council level, but often the guidelines are applicable to larger areas, such as states/ provinces, regions or sub-regions, or smaller areas, such as a suburb or urban fringe development area. Some of the guidelines cover provision for a wide range of leisure activity, while others are concerned with just one sector, such as cultural provision, or one type of facility, such as open space, but guidelines for the conduct of feasibility studies for a single facility were not included. Also excluded, were 'impact management systems', such a VAMP and VIM (Moore and Driver, 2005: 167), which are designed for the management of a single estate, such as a National Park service, although one such system, the Recreation Opportunity Spectrum, is included, since it has been promoted for wider use. The 80 documents included were identified using an informal 'snowball' process, with one source in the leisure planning literature leading to others.

Table 2 presents a summary of some of the features of the guidelines. It shows that the bulk of the items (51) were in the form of reports, published by government, government agencies and professional or industry bodies. Only two were articles in refereed journals. The bulk of the academic contributions were in the form of books, of which 13 were textbooks, including multiple editions. In the latter case, the first and latest editions, and any intervening editions which included significant change to the planning content, are included in the review. Of note in the non-academic documents, is that there is an almost complete lack of reference to academic sources, or even to previous guidelines. Most of the documents were written by government, government agency, or professional or industry body officials, but many of the official reports were written by consultants, including academics. Bearing in mind that most 
Table 2. Summary of guideline document characteristics

\begin{tabular}{|c|c|c|c|c|c|}
\hline & $1965-79$ & $1980-89$ & $1990-99$ & $2000-11$ & Total \\
\hline \multicolumn{6}{|c|}{ Activity-groups covered (some reports include more than one category) } \\
\hline Recreation & 8 & 4 & 4 & 7 & 23 \\
\hline Leisure & 4 & 5 & 6 & 5 & 20 \\
\hline Tourism & 2 & 1 & 7 & 5 & 15 \\
\hline Sport & 2 & 1 & 4 & 7 & 14 \\
\hline Open space & 4 & 3 & 3 & 4 & 14 \\
\hline Culture & 0 & 0 & 3 & 3 & 6 \\
\hline Other & 2 & 0 & 1 & 2 & 5 \\
\hline \multicolumn{6}{|l|}{ Type of publication } \\
\hline Government/official report & 14 & 8 & 17 & 14 & 53 \\
\hline \multicolumn{6}{|c|}{ Commercially published textbook* } \\
\hline - first edition & 2 & 2 & 1 & 1 & 6 \\
\hline - second and later editions & 0 & 0 & 3 & 4 & 7 \\
\hline Other book/book chapter & 3 & 2 & 3 & 4 & 12 \\
\hline Refereed journal article & 0 & 0 & 2 & 0 & 2 \\
\hline Academic working paper & 1 & 1 & 0 & 0 & 2 \\
\hline \multicolumn{6}{|l|}{ Country } \\
\hline Australia & 4 & 4 & 8 & 9 & 25 \\
\hline Canada & 4 & 1 & 0 & 0 & 5 \\
\hline UK & 3 & 2 & 5 & 7 & 17 \\
\hline USA & 7 & 6 & 10 & 5 & 28 \\
\hline Other & 2 & 1 & 3 & 2 & 7 \\
\hline \multicolumn{6}{|l|}{ Sponsor } \\
\hline Academic & 7 & 5 & 9 & 10 & 31 \\
\hline Government $* *$ & 10 & 6 & 11 & 9 & 36 \\
\hline Industry & 2 & 0 & 4 & 3 & 9 \\
\hline Other & 1 & 2 & 2 & 1 & 6 \\
\hline \multicolumn{6}{|l|}{ Primary approach } \\
\hline Benefits/econ. impact & 2 & 1 & 7 & 4 & 14 \\
\hline Demand & 8 & 2 & 5 & 3 & 18 \\
\hline Need & 1 & 5 & 4 & 1 & 11 \\
\hline Stakeholder consultation & 1 & 2 & 6 & 4 & 13 \\
\hline Standards & 6 & 1 & 0 & 6 & 13 \\
\hline Other/various $\dagger$ & 2 & 2 & 4 & 5 & 13 \\
\hline Total documents & 20 & 13 & 26 & 23 & 82 \\
\hline
\end{tabular}

- *The first and latest editions of textbooks are included and any intervening editions with significantly changed planning content.

- ** In many cases government reports are commissioned from consultants.

- † This refers to three textbooks which describe a number of alternative approaches. 
of the documents have more than one activity group in their title, the most commonly occurring activities were recreation (21), leisure (20), tourism (15), sport (14) and open space (13). Culture (6) is invariably presented as a single focus ${ }^{2}$. Most important for this review are the main types of goal and implied planning approaches recommended in the documents, which can be summarised under eight headings: 1. meeting provision standards; 2. providing opportunity; 3. managing natural/heritage resources; 4. meeting demand; 5. satisfying stakeholder groups; 6 . meeting needs; 7. setting and meeting participation targets; and 8. providing benefits. Two of these (4 and 8 ) are sub-divided, giving ten approaches in all. Before discussing these in turn, six general issues which emerged from the review of guidelines are discussed briefly.

Given that the selection criteria included the presence of 'how-to-do-it' advice on planning to improve service provision and the quality of life within broadly liberal-democratic environments, all the guidelines are ideologically located in the reformist, pluralist tradition. It is assumed that the sorts of planning exercise discussed are conducted or commissioned by a legitimately elected body, such as a local council, or a body appointed by an elected government, such as a board of trustees. Such organisations will lie politically somewhere between the social democratic left and the neo-liberal right, the former associated with extensive state activity and social equality and the latter more inclined to a minimal role for the state and individual enterprise. It is assumed that a range of public, private/commercial and voluntary sector organisations are involved in the provision of leisure, sport, tourism and arts services. This general contextual framework is accepted within this paper.

2. A feature of the guidelines is that they all adopt a broadly rational-comprehensive decision-making framework. This involves a complete appraisal of the whole system being examined, for example a leisure or tourism 'system' (Mill and Morrison, 2006; Murphy et al., 1991), and seeking to find an optimum solution to the task in hand. Alternative, more realistic approaches to decision-making and planning have been proposed, such as Etzioni's (1967) 'mixed scanning', which accepts that a fully comprehensive approach is impractical or too expensive or lengthy. Such an approach has emerged in the leisure planning context, in the form of the 'issues approach' (Veal, 2002: 146; Heritage, Conservation and Recreation Service, 1979), but while some of the guidelines reviewed here include 'identification of issues' as one of a number of functions of stakeholder consultation, none stresses this as an approach in its own right .

.3. It is often surprisingly difficult to determine the primary policymaking/planning approach being recommended in the guidelines. This is largely because the content of many of the documents is dominated by generic descriptions of tasks in the generic rationalcomprehensive policy-making/decision-making process, such as: a review of current policies; goal-setting; inventory compilation; demand/need/ participation data collection; consultation with stakeholders; data analysis; and report preparation. But there is little discussion of the types of goal which might emerge and the implications of these for the methodology, including the type of data to be collected and how it should be analysed. By way of comparison, it is as if guidelines for transport planning contained advice on how to carry out traffic surveys but not on how to model travel flows and alternative patterns of infrastructure provision and evaluate them.

${ }^{2}$ Reports on 'cultural planning', while initially offering a wide definition of 'culture', covering a whole way of life, invariably focus, in practice, on a narrower range of arts provision. 
4. Following from the previous point: while the guidelines recommend, and often provide extensive guidance on, data collection, little if any advice is offered on data analysis. Words like 'appraisal' and 'analysis' are used, but little guidance is offered on, for example, how various types of data, such as participation survey results, and stakeholder opinion, should be analysed to shape policy. A 'black box' is implicit: data goes in one end and policies come out of the other.

5. Following from the previous two points, a lack of clarity about planning approaches is often compounded by the fact that multiple approaches appear to be in play within a rationalcomprehensive framework. Different planning approaches require different types of data input and output, so lack of clarity about approaches and their relationships gives rise to the data analysis problem. If two or more planning approaches are to be utilised, the question arises as to how they relate to one another and how possibly conflicting inputs and outputs should be reconciled. If one approach is adopted in order to overcome weaknesses in another, then one would think it would be helpful to users of the guidelines for such weaknesses, and the ways in which they may be overcome, to be spelled out. This is rarely if ever done in the documents reviewed. And it might be thought that an overall process which involves the deployment of two or more complementary techniques, both of which are required to achieve one overall purpose, would itself become a recognisable composite process or approach. This has not happened in the evolution of the guidelines reviewed.

6. There is generally a lack of attention to evaluation in the guidelines. General policymaking/planning models (such as Figure 1 discussed below) invariably include an evaluation stage in which implementation is monitored, typically using key performance indicators. This is now quite common in strategic organisational and facility management in the leisure, sport, tourism and arts sectors (see Alexandris, 2008). This process requires managers to specify assessable performance indicators related to the goals and objectives of the organisation and can have the effect of causing managers/planners/decision-makers to think clearly about both the goals and objectives of the management/planning operation and their intended outcomes.

\section{A generic planning model}

Figure 1, which draws on a diagram of the 'recreation production process' by Driver and Bruns (1999), is a generic model of the leisure planning process designed to assist in understanding relationships between various approaches to leisure planning. It shows a series of stakeholders , a series of four inputs and four outputs and the planning process itself. Facilities/services/opportunities are both an output of the first part of the process and an input to the second part, the facilitation of leisure activity. The logical flow of the model is that the ultimate output of the process lies in Outputs 4, the net benefits produced, while Outputs 1, 2 and 3 are means to that end. The planning process first seeks to establish the status quo regarding facilities/services/opportunities, facility/service use/visits/participation and net benefits, then establishes a future changed state which implementation of the plan is intended to achieve: reaching this state is likely to be an iterative process. As implementation proceeds, it is tracked by a monitoring and evaluation feedback process. Reference is made to the model in the discussion which follows. 
Figure 1. A generic planning model

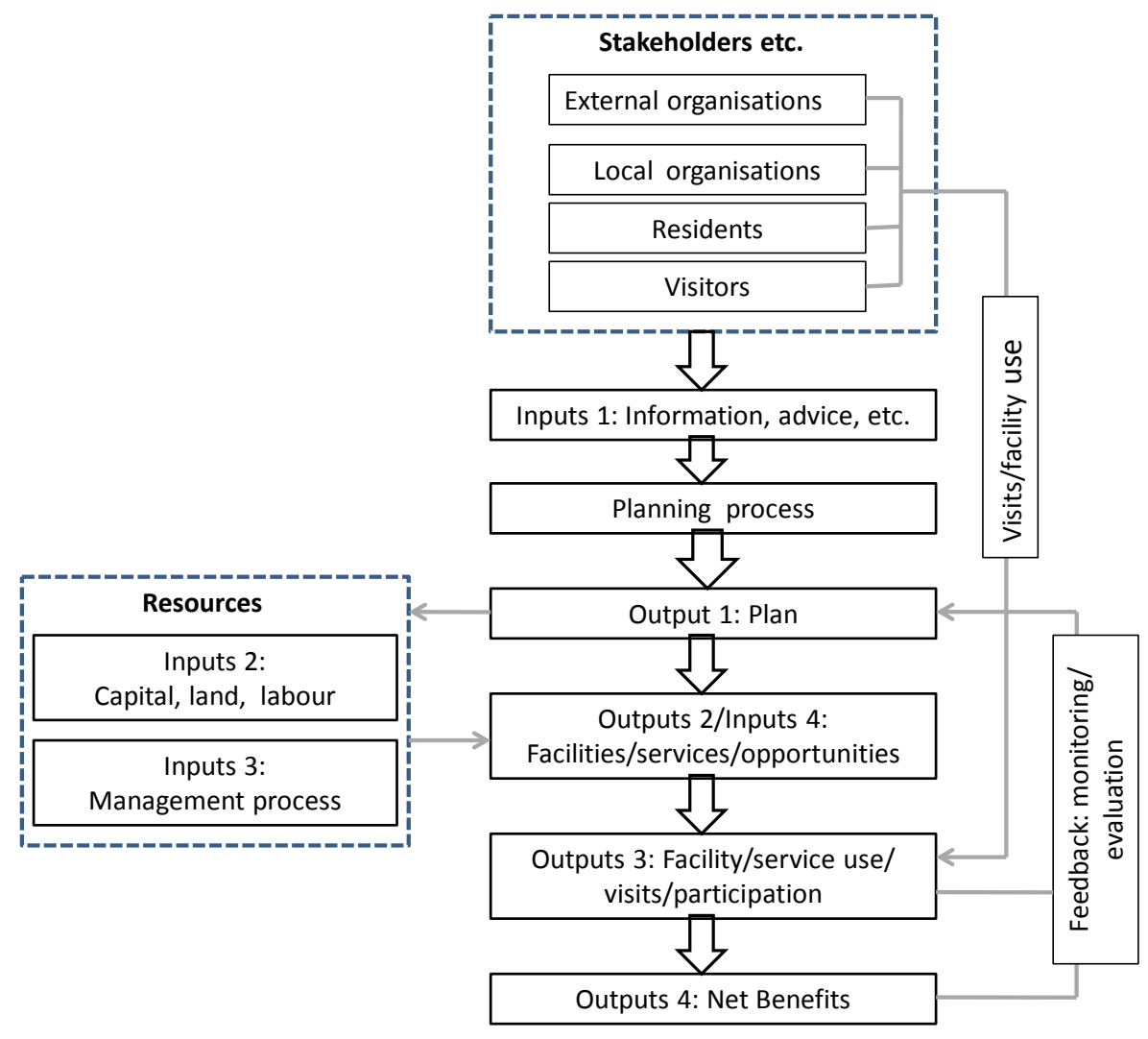

\section{Rationales, goals and associated planning approaches identified in the guidelines}

\section{Meeting provision standards}

A number of types of standard is used in leisure planning and management, including: 1. safety standards related to the design process; 2 . specification standards related to the required dimensions and equipment of sporting and other facilities; and 3. locally-specific provision standards, themselves derived on the basis of approaches such as those discussed in this paper. Here we are concerned with a fourth type: fixed provision standards promulgated by an external authoritative organisation, generally expressed as a level of provision of facilities per 1000 population. The most well-known of these are public open space standards, although they also exist for a range of sporting facilities and for libraries (see, for example, Torkildsen, 2005: 239). Provision standards are not common in the tourism sector, but BaudBovy and Lawson (1998: 46, 53) have presented such standards for purpose-built holiday resorts. Typically, a local plan based on provision standards will simply state that the proposed provision is based on the standards recommended by the promulgating organisation. So the planning body utilising the standard is implicitly accepting the goals and norms of the external organisation, whatever they might be. In terms of Figure 1, the inputs are the prescribed standard and the size of the population being planned for: the question of outputs goes no further than Outputs 2, the facilities/services provided. 
The use of fixed provision standards of course begs the question: how were the standards arrived at? The answer is often unclear from the documentation available. For example, the precise original basis of the American open space standards is not known, even by the National Recreation and Parks Association which promulgated them (Wilkinson, 1985). They were abandoned in 1996 (Mertes and Hall, 1996). In the case of the British-based playing space standard, promulgated by Fields in Trust (previously the National Playing Fields Association), the playing fields component was originally based on estimates of sporting participation rates in Britain in the 1920s (Fields in Trust, 2008: Appendix A). It has remained substantially unchanged ever since, and there is no evidence that more recent participation data have been used in its various updates. The technical basis of the children's play space component has not been documented.

Fixed provision standards have been subject to substantial criticism for at least 40 years (Sports Council, 1968; Marriott, 1980, Veal, 2006: 119-21), largely on the grounds that a 'one-size-fits-all' approach is not appropriate and that leisure service requirements should be locally assessed, taking account of local conditions. In particular, adopting a goal expressed solely in terms of provision of facilities/services, begs the question of what the facilities/ services are for: in other words, it ignores Outputs 3 and 4 in Figure 1. As a result of these criticisms, many official guidelines now advise against the use of fixed provision standards. Nevertheless, they still have a presence in parts of the planning and provision system. As noted above, Fields in Trust still promotes its long-standing playing space standard and its 2008 report noted that it was still 'widely used' by local government in England (Fields in Trust, 2008: Appendix D). Standards appear to be particularly attractive to developers and environmental courts, where council planning decisions are often disputed. They are also favoured by non-specialist town planners. Thus, for example, as recently as 2008, a set of guidelines for the planning of a wide range of 'community infrastructure' in new development areas in five council areas in greater Melbourne included provision standards for 'indoor recreation', 'active outdoor sport and recreation' and 'libraries, arts and cultural facilities' (Australian Social and Recreation Research, 2008). A recently published American urban planning textbook refers to the document in which the National Recreation Parks Association ceased its endorsement of standards and recommended alternative planning methodologies, but the book nevertheless states that the NRPA does recommend standards and devotes two pages to reproducing its obsolete 1983 standards (Berke, Godschalk, Kaiser and Rodriguez., 2006: 416-17).

The major limitation of fixed standards, as put forward by critics of the approach, is often recognised by their proponents. A common feature of documents recommending the use of provision standards is their suggestion that the standards may need to be modified in light of local conditions. For example, Fields in Trust (2008: Appendix C) states:

Clearly, there still remains the need for local assessment but the use of Fields in Trust recommendations as quantitative Benchmark Standards carry [sic] general value. Fields in Trust does, however, recognise that there will be variations both below and above the Fields in Trust Benchmark standards.

No guidance is provided regarding the basis for the 'local assessment' or the reasons why there might be 'variations'. In some cases, some general indications are given as to what factors might be taken into account (e.g., Sport and Recreation Queensland, 2003: 52), but the question then arises as to why such factors are not used to establish provision 
requirements in the first place. Thus, for example, if the standard is varied because of varying demographic characteristics of local populations and the differing participation patterns of different demographic groups, why is the provision level not determined using these criteria in the first place, that is, by using the gross demand method discussed below?

\section{Providing opportunity}

As the authors of most official planning guidelines, plans and strategies sought to discourage the use of nationally derived provision standards, which had reflected a 'top down' approach, a replacement approach was called for. Expressing goals in terms of 'providing opportunity' seemed to provide a suitable 'bottom up' alternative. Examples of such goals put forward in a number of sets guidelines include: 'To provide recreational opportunities to every citizen' (Ontario Ministry of Culture and Recreation, 1979: 14); 'To provide recreation opportunities for all people regardless of age, sex, religion or culture' (British Columbia, Recreation and Sport Branch, 1980: 10); and 'To ensure a diverse, safe, conveniently accessible leisure environment which provides opportunities for the satisfaction of a range of recreation pursuits for all sections of the community' (Marriott, 1987: 123). Furthermore, Marriott (2010: 12) states: 'The provision of opportunities for the community to take part in a wide mix of recreation activities and programmes should be a central goal of good recreation planning'.

The opportunities terminology is often accompanied by statements to the effect that governments should not 'tell people what to do in their leisure time'. For example, in a 1985 policy document, the Australian government stated: 'Governments are not concerned with telling people how to spend their time but rather with ensuring that opportunities exist and that individuals have the knowledge to make informed choices' (Brown, 1985: 8). A 2002 British government document, Game Plan, stated: 'While the government cannot, and should not, compel people to participate in sporting activities, it might wish to intervene to help remove the barriers that lead to inequality of opportunity' (DCMS/Strategy Unit, 2002: 78).

Of course, although governments at all levels seek to encourage participation in some activities (e.g., sport or the arts) and discourage participation in others (e.g., illicit drugtaking), it cannot coerce people to engage in prescribed leisure activities. Providing opportunity is what all leisure service providers do, but provision of opportunity is a means to an end, not the end itself. For example, if an organisation provides a 'swimming opportunity' in the form of a swimming pool and it attracts no users, the policy will be judged a failure: there is no point in providing opportunities if they are not taken advantage of by the people for whom they were intended. The ultimate goal of the provision of opportunity must therefore be something to do with the use of the facility or service, which suggests that some other rationale, such as demand, need or participation, as discussed below, is involved. Thus, if the term opportunity is to be used in goal statements at all, it would make sense for it to be coupled with some reference to goals related to the reasons why the opportunities are being provided. In terms of Figure 1, expressing goals in terms of the provision of opportunity suggests that, as with the standards approach, the process ends at Outputs 2. At best they are an interim goal as a means to delivering Outputs 3 and 4.

A feature of opportunity statements, as in the examples quoted above, is the aim of providing a range or diversity of opportunities to meet the requirements of a diversity of groups in the community. Some expressions of the goal imply that this is on equity grounds, but it could also relate to the private sector concept of market segmentation which seeks to maximise 
sales by matching variations in products/services as closely as possible to variations in market segment demands. Either way, the aim is maximisation of sales or participation (Outputs 3), suggesting some connection with participation as a goal.

\section{Managing (natural/heritage) resources}

Resource-based planning has an even longer history in leisure planning than the use of standards. It is clear that if natural or heritage resources are involved in a planning project, then conservation values and decision-making criteria come into play, and in some cases they may be dominant. But these are distinct from leisure considerations, as is illustrated by the fact that substantial parts of the collections of most museums and galleries are not on public display and large areas of wilderness and nature reserves are closed to the public - that is, they are conserved for their own sake or for scientific purposes, not for the purpose of public leisure enjoyment. Assessing the requirements for leisure requires a set of skills and procedures which are different from those required to assess the value of a natural, environmental or heritage resource. Once the two forms of assessment have been carried out, planners and decision-makers must juggle the conservation and leisure requirements to arrive at decisions. This may be relatively easy or difficult, depending on whether the two are complementary or in conflict.

A popular example of a resource-based methodology is the Recreation Opportunity Spectrum (ROS) devised by Clark and Stankey (1979; Stankey, McCool, Clark, and Brown, 1999). It classifies areas, or 'settings', in which people might seek outdoor recreation along a continuum from the totally undeveloped, such as pristine wilderness ('primitive'), to the highly developed, such as a fully serviced camping site and recreation area ('modern'). Against this are set the sorts of activity which the management and other users of these areas (e.g., foresters) might engage in to maintain the appropriate 'ambience' of the site and compatibility with visitor expectations. The system arose from the US Forest Service, where the two authors, Clark and Stankey, were employed, but has been adopted more widely (e.g. Jackson, 1986). The above discussion clearly applies to the conservation aspects of the system. But the recreational aspects require additional methodological input. The fact that the physical characteristics of an area make it suitable to accommodate a certain amount and type of recreational activity, does not automatically imply that provision for that amount and type of recreational activity should be made in that location. It at least requires an analysis of the relevant demand and the wider supply situation. Thus, while the ROS system may play a part in environments where natural resources are significantly involved, it alone is not a sufficient basis for recreational planning.

In terms of Figure 1, resource evaluation can be seen as part of Inputs 2, in that some of the land and other resources are subject to capacity constraints and/or restricted to particular types of activities.

\section{Meeting demand}

Demand-based planning has been used particularly in relation to tourism and countryside recreation, less so in other sectors. Demand, as used in leisure planning and policymaking, has generally been viewed as an economic relationship which, in its simplest form, refers to the way the amount of a good or service which a consumer is willing to purchase, varies according to the price. This has not presented a problem in tourism planning, but has caused some concern and confusion in sectors with greater public sector involvement, resulting in its rejection by a number of commentators. Thus, for example, Kelly (1983: 172) and Evans 
(2001: 115) reject its use in leisure and cultural planning respectively because they believe 'demand' is equated with 'current effective demand', and that therefore 'latent, excess or unrealised demand' is ignored. But they fail to recognise that if demand is a relationship between price and quantities which will be purchased (as illustrated by the familiar price/ demand curve) then current effective demand is just one point on the demand curve reflecting current price and current supply conditions. So, for example, demand could be expected to increase when prices are reduced, thus satisfying at least some of the 'latent, excess or unrealised demand'. Furthermore, since using leisure facilities involves travel to a site, the 'price' of access can be interpreted as a combination of entry price and travel cost, so increasing the level of supply and spread of facilities will generally reduce the average distance travelled, and hence the average travel cost, resulting in increased effective demand. Thus policy is based on an understanding of the relationship between price, other supply conditions and demand. It is true that some early demand-based planning failed to fully reflect this principle, although the well-known 'Clawson method' for deriving a demand curve from data on existing demand patterns did reflect the theory and was developed as early as the 1960s (Clawson and Knetsch, 1967). More recent demand modelling has developed considerably, taking account of the capacity and quality of supply and of the existence of different user groups (see Hanley et al., 2003).

In addition to the issue of current versus latent demand, a second source of confusion is that the simple economic definition of demand referred to above implies that, in a demand-based planning approach, the only policy lever available is price, and this has been associated in some people's minds with the private sector and such concepts as 'user pays' and privatisation. This perception persists despite the fact that the bulk of research in the 'economics of leisure' has been concerned with situations where entry prices are zero (e.g., urban parks, some natural area sites, some museums and galleries) or subsidised (e.g., theatres, playing fields, sports centres) (Veal, 2006). Thus demand models seek to understand demand dynamics in relation to a range of possible pricing regimes, in addition to user characteristics and additional supply variables as discussed above, the very variables upon which policy operates. Models are constructed on the basis of existing facilities/services and then applied to hypothetical new facilities/services to predict demand.

However, while a demand model can predict levels of demand in varying supply conditions, it does not of itself determine what those supply conditions should be. The level of demand can be almost open-ended, depending on how generous the supply conditions become. To determine some sort of reasonable limit within the economic framework requires the use of cost-benefit analysis, so the limit lies at the point where the costs of provision begin to exceed the benefits generated or where the internal rate of return falls below an acceptable level. This in turn requires the consideration of benefits, as discussed below.

Despite the recognition of the economic definition of demand in the literature, this is not how the concept is used in the guidelines, although it is implicit in tourism-related guidelines as a component of the economic benefits/impact model typically used. In the guidelines, demand appears in the form of the 'gross demand' and 'organic' or 'incremental' approaches, which can be seen as very simplified versions of demand models. The gross demand approach seeks to estimate total participation levels within a community, typically using current local, regional or national age/gender-specific participation rates and forecasts of the future size of gender/age groups Thus the method is limited by its assumption that local participation rates are assumed to remain constant or that all communities will be planned on the basis of current 
regional or national age/gender-specific rates. In the case of tourism, demand - in the form of predicted or possible visit numbers and/or expenditure - is generally estimated in the context of national or regional demand projections.

The organic or incremental approach is based on examination of the use of existing facilities. Underused facilities indicate more than adequate provision for that type of facility/activity. Over-use, indicated by such factors as overcrowding and full waiting lists, indicates excess demand and grounds for increased provision. Spatial analysis is added to establish catchment areas to identify served and unserved areas, with unserved areas giving grounds for additional provision. This approach is limited by the very fact that it is based on existing facilities and facility/activity-specific analysis.

In terms of the model in Figure 1, both of these approaches focus on Outputs 3 as the outcome of the planning process.

\section{Satisfying stakeholder groups}

Consulting stakeholder groups is another 'bottom up' approach which has come to the fore in place of the use of standards. Of course, stakeholder consultation has a role to play in all planning, and for some types of planning it is a statutory requirement. Stakeholder consultation produces four types of information: 1. Factual information, from individuals (e.g. leisure participation patterns, socio-economic characteristics of facility users) or from relevant organisations (e.g. membership data); 2. Information on individuals' own leisure activity aspirations and perceived constraints and requests from individuals and organisations on facility and service provision; 3. Innovative ideas; and 4. Opinions sought by decisionmakers in the form of a plebiscite regarding priorities and preferred options. Here we are concerned with Type 2 information. Type 1 information is related to demand and participation approaches. Type 3 information could relate to, and would be evaluated via, a number of the approaches. Type 4 information is that sought by a decision-making body at any point in the planning process where it wishes to insert a democratic components into key decision-making, for example, on vision/goals or strategic priorities. Type 2 information is typically gathered by means of surveys, focus groups and public meetings. In a number of sets of guidelines, the amount of emphasis given to this process and the fact that the nature of the information gathered, in the form of the desire to participate and requests for facilities and services, seems to feed directly into policy recommendations, leads to the conclusion that this is the main approach to planning being adopted.

In terms of Figure 1, planning which is based on stakeholder information regarding desired facilities/services sees the planning process ending with the provision of the requested facilities/services (Outputs 2), although it would be anticipated that such facilities/ services would then be made use of. When information on personal aspirations for participation in an activity is involved, the process ends when the desired participation takes place (Outputs 3).

It should be said that none of the guidelines suggests that the main planning goal is 'to satisfy stakeholder groups'. They tend to use statements such as 'to meet community needs'. But a simplistic strategy of 'asking people what they want' is implicit. It can be speculated that this would appeal to elected members of councils because it suggests a quasi-democratic process. The issue of 'needs' is discussed below; what is examined here is the proposition that stakeholder consultation can provide the main source of information - on needs or on other matters - upon which to base a plan. 
Stakeholder groups can be divided into two types: organised and non-organised. Organised groups are generally consulted via representatives. Four grounds exist for exercising caution in regard to the use of information from this source. First, response rates from some sectors, such as local sports clubs, are often very low, giving rise to questions about representativeness of the responses received. Second, there is research to suggest that in some sectors, the views of group representatives are not typical of those of the group membership, let alone of non-member participants (Lord and Elmendorf, 2008). Arguably, further research in a variety of contexts is required on this topic. Third, representatives vary in their advocacy skills and in their level of knowledge and expertise in regard to the activity they represent and the planning/ policymaking process. Fourth, representatives are, by definition, biased in favour of their activity to varying degrees.

Non-organised members of the community are generally consulted via questionnaire-based survey or focus group and sometimes by other means such as public meetings. Questionnairebased surveys are generally representative if they are professionally conducted. Focus group and public meeting attendees may be representative in a broad way, but not sufficiently to enable findings to be quantified. Typically survey respondents are asked to indicate what activities they would like to, or are planning to, take part in, and the constraints preventing them from doing so. But a question arises as to the relationship between responses to such questions and actual behaviour when or if the constraints are removed, for example, by provision of facilities. Market researchers in other sectors have for decades raised doubts about the reliability of declared intentions or aspirations as a straightforward guide to future behaviour (e.g., Packard, 1957: 13-16). Some of the guidelines express caution about this issue (e.g., WA Sport and Recreation, 1997: 14; Marriott, 2010: 81), but clear solutions are not forthcoming.

There is, however, a problem common to both types of stakeholder consultation: that is, how to analyse the range of information gathered. It is reasonable to assume that Type 2 information will consist essentially of a number of 'shopping lists' from various sources. These will comprise lists of: activities people would like to engage in, quantified in the case of survey research but qualitative in the case of other sources; constraints preventing participation; and views on what facilities/services should be provided. Often these will be associated with different groups, on the basis of socio-demographic information in questionnaires, the make-up of focus groups or the location of public meetings. With few exceptions (e.g. Grogan and Mercer, 1995: 103), no mention is made in the guidelines of the 'shopping list' phenomenon, so no advice is offered on how they should be analysed to formulate policy recommendations. The criteria and processes used to evaluate the information and shape policy recommendations can be said to enshrine the core of the planning process. Typically, however, such criteria and processes are not discussed in the guidelines: the process is again a 'black box'.

It is possible to speculate as to what guidance could be offered on this matter, and possibly, what goes on in practice. Two examples are discussed briefly here. One expression used in the guidelines is the 'determination of priorities', since it would rarely if ever be possible to proceed with all the items on all the shopping lists. Many local councils have strong social equity policies, involving target priority groups, such as youth at risk or the elderly. Thus the views of such groups could be given precedence. But this leaves open the question of service provision to non-priority groups. This is, of course, likely to be only a partial solution. In all 
cases, the question of demand will arise, particularly where large investments are concerned. So, for example, if the residents of a particular area express a wish to go swimming, or call for the provision of a swimming pool, some assessment of expected demand from the estimated catchment area is likely to be made and if it is less than that required to justify the provision of the smallest viable swimming pool, the proposal could well be rejected on those grounds. Here the 'gross demand' approach takes precedence over stakeholder consultation. None of the guidelines works through these sorts of possibility, so one is left wondering what the relationships are between the various explicit and implicit approaches involved.

\section{Meeting needs}

Many sets of planning guidelines published in the last 20 years advise planners to assess 'community needs', but none of them defines what is meant by 'need'. One of the difficulties here is that the word need is used in different senses. Paul Taylor (1959) identified four different uses of the term, as follows.

1. Something needed to satisfy a law or rule - for example, the need for a certificate to referee a sporting contest or the need to have a ticket to be admitted to an event.

2. A means to an end (specified or implied) - for example, the need for a racquet to play tennis or for food to sustain life.

3. Certain 'conscious or unconscious wants, motivations, drives, desires' - for example, people's need for excitement, variety, achievement, or the taste of chocolate. Taylor suggests 'Needs in this sense constitute conative dispositions'.

4. Recommendations or normative evaluations.

In the commercial sector, the third meaning is typically used in relation to all types of consumer products (see, for example, the shelves in supermarkets labelled 'party needs'), including tourism. However, in the public sector efforts have been made by leisure

policymakers to adopt the fourth type of meaning in order to align leisure with mainstream social services, such as health or education. Hence the famous statement:

Until Parliament, government, planners and educators accept the place of leisure as an essential ingredient of life, there will be no satisfactory provision of recreational facilities, and the well-being of the community will suffer. Society ought to regard sport and leisure not as a slightly eccentric form of indulgence but as one of the community's everyday needs. (House of Lords Select Committee on Sport and Leisure, 1973: xxvi)

More recently, the following appeared in a set of Australian cultural planning guidelines: '... cultural amenities can be seen not as something remote or apart from everyday life but fundamental to people's needs' (NSW Ministry for the Arts \& Dept of Local Government, 2002: 2).

There is an enormous theoretical literature on the concept of need, in various disciplines, but two sources stand out in the leisure context. Reference is, implicitly or explicitly, made to theoretical frameworks such as Abraham Maslow's 1954/1987) well-known 'hierarchy of needs' and to the typology of need put forward by David Mercer (1973), based on the work of Jonathan Bradshaw (1972). 
References to Maslow do not generally appear in planning guidelines, which do not tend to refer to academic sources, but they do appear in some research publications (e.g., Ravenscroft, 1993) and in numerous textbooks, examples of which can be found in tourism (Kotler, Bowen and Makens, 2006: 14, 212), leisure (Broadhurst, 2001: 11; Taylor, 2011: 28) and the arts (Bernstein (2007: 81-2, 84), with Hall and Page (2006: 37) observing that Maslow's research has shaped 'much of the recreation and tourism demand work'. Typically, however, authors focus on the hierarchy idea and ignore Maslow's definition of a basic need, encapsulated in his statement: 'Thwarting of unimportant desires produces no psychopathological results: thwarting of basically important needs does produce such results' (Maslow, 1954/1987: 30). Thus the Maslow’s hierarchy refers to 'basically important needs' which is a desire that, if thwarted, results in harm to the individual. It does not refer to 'unimportant desires'. This harm-related definition of need has been endorsed by more recent authors (e.g., Doyal and Gough, 1991; Elkins and Max-Neef, 1992). Such a definition is of Taylor's type four, since a normative position has to be adopted as to what constitutes harm. In Maslow's case, such assessments were made in the context of psycho-therapy. Applying the Maslovian conception of need to leisure is therefore to suggest that certain forms of leisure activity, if denied, would result in harm to the individual or the community. Hence the statements from the House of Lords and the New South Wales government quoted above. Indeed, in the White Paper which endorsed the House of Lords view, the British government of the time spoke of the widespread stress being experienced by young people and added: 'Where the community neglects its responsibilities for providing the individual with opportunities and choice in the provision of sports and recreational facilities, it will rarely escape the long-term consequences of this neglect' (Department of the Environment, 1975: 19).

These sentiments are, of course, reflected in a number of the widely accepted arguments for public provision of leisure services, such as the prevention of poor health through exercise and the belief, despite the paucity of good supporting evidence (Nichols, 2007), in the crime prevention qualities of certain forms of leisure provision. Desires which are not needs in this sense might be referred to as 'wants'. But, as Robert Paddick has put it: 'The inclination to call a great many things 'needs' is not difficult to appreciate. At least part of the answer is that 'need' is a particularly powerful planning concept, because we are much more likely to gain acceptance for giving people what they need, than for giving them what they want' (Paddick, 1982: 41). In practice, however, public facilities do not only meet needs in this sense, they cater to needs and wants. People may make use of public leisure services to satisfy a variety of desires and those who do not satisfy the criterion of 'need' cannot be excluded. This is in fact reflected in the usage of the 'need' in policy documents such as the guidelines under review: they are in fact using it in Taylor's third, non-normative sense. But statements such as those of the House of Lords and the New South Wales government suggest that the leisure sector, including sport and the arts, but not tourism, is happy to be associated with the rhetoric of the normative harm prevention connotations of need.

The Bradshaw/Mercer typology comprises: 1. Expressed need (what people currently do, or actively seek to do by, for example, putting their names on a waiting list); 2 . Felt need (what people say they would like to do); 3. Comparative need (deficiencies indicated by comparison with others); and 4. Normative need (need based on normative criteria as defined by experts or, possibly, an elected body or pressure group or the general public). As with the Maslow theory, this typology is also referred to in textbooks (e.g., Pigram and Jenkins, 2006: 59; Page and Connell, 2010: 141; Taylor, 2011: 32-3). In the guideline documents the source 
is generally not formally referenced, except in the textbooks, but exists in the use of the terminology, as in one of the more recent sets of guidelines (Marriott, 2010: 84, 88). However, neither Bradshaw nor Mercer actually define need. As Elery Hamilton-Smith (1975) and others have observed, the typology does not define four different types of need as much as four ways of measuring need, regardless of how the latter is defined. It was not necessary for Bradshaw to provide such a definition, since he was writing in the context of the mainstream social services in Britain, the needs-based status of which was not in question. But Mercer recognises that this is an issue in relation to leisure, querying the basis of existing claims at the time, but then going on to assume that leisure is a 'social need', but without defining it.

In the guidelines it is invariably recommended that felt needs be assessed by means of consultative processes such as questionnaire-based surveys, examples of which ask residents about such things as their 'level of interest' in activities (Mclean et al., 1999: 352), or direct suggestions for facilities/services they would like to see provided (Marriott, 2010: 83). But a curious feature of such 'leisure needs' questionnaires is that, typically, they do not ask respondents what they need. They do not, therefore, assess needs alone but needs and wants together. So, unless needs and wants are deemed to be the same thing, it is misleading to claim that a plan based on such surveys is catering only to 'needs'. Given this context, the socalled needs-based approach is subject to the same reservations as the survey-based individual stakeholder consultation approach discussed above. As with individual stakeholder consultation, the needs-based approach is focussed on Outputs 2 or Outputs 3 in Figure 1, depending on the type of information gathered. (For an extended treatment of the concept of need and its relationships with leisure, see Veal, 2011b.)

\section{Meeting participation targets}

The setting of participation targets is an exception in this review, in that it does not emerge as a common approach in the guidelines - only one, a recent textbook describes it (Veal, 2010) - but it has emerged recently in practice. In its current strategic plan Sport England (2008) has set a target of one million more people participating in sport over five years. Participation targets in sport and physical activity have been set by a number of local councils in Britain as part of the central-local government Local Area Agreements ${ }^{3}$ system, linked to the Sport England annual Active People participation survey (see, for example, Birmingham City Council, 2007). In Australia, the New South Wales 2006 State Plan (NSW Dept of Arts, Sport and Recreation, 2007) sets participation targets for sport/physical activity, arts participation and parks visits. These initiatives have arisen from performance evaluation processes, rather than strategic planning but, of course, these processes are linked, since performance evaluation is part of the process of ensuring that plans are successfully implemented. In some cases, participation is recognised as the focus for the planning process, even if the plan does not go as far as to set targets. For example, the vision statement for the 2003 recreation strategy of the City of Ballarat, Victoria, Australia, included:

Sustainable and life-long participation in recreation on the part of all members of the ... community so as to deliver the optimum array of personal, social,

\footnotetext{
3 The recently elected Conservative/Liberal-Democrat government has terminated the Local Area Agreements system and its associated National Indicator reporting, as a cost-cutting measure (see Department of Communities and Local Govt (2011)), but the Active People survey is funded by Sport England, which is itself partly funded from the National Lottery, so it is likely to continue and it remains to be seen whether individual local councils will continue with participation-based planning.
} 
economic and environmental benefits and the optimal level of community building and social capital development. (Quoted in Marriott, 2010: 20)

The approach involves the setting of participation targets, both overall and for different geographical areas or planning zones and/or different socio-economic groups. Participation rates are measured by social survey at the start of the planning period, at its conclusion and possibly at points in between (and, in a performance evaluation system, possibly annually). Targets are set for generic groups of activity, such as sport/physical activity and arts/cultural activity. Detailed work is then undertaken to establish the most effective way of achieving the target in a particular local context - for example, by considering the types of activity most likely to be successful and whether to provide new facilities, increase the capacity of existing facilities, develop targeted programmes, offer grants or conduct educational or publicity campaigns. The approach permits a variety of pathways to achieving the targets, reflecting local conditions: for example, the same level of participation in sport/physical activity might be achieved in a high density inner urban area by provision of indoor and hard surface facilities for basketball and badminton, but in a low density suburban area by provision of grass playing fields for various team games and greenways for walking and cycling.

The question arises: How should the targets be set? In the examples mentioned above, the targets are quite modest and no particular rationale has been published. One possibility is to begin by using social or spatial equity as a criterion: that is, setting targets to bring low participant groups or areas up to the average, which, when achieved, would gradually increase the overall average participation rate. This could be done in regard to social groups or zones within a planning area, and/or by comparison between planning areas if comparable data are available. Over the longer term, the setting of higher targets would probably require the involvement of state and/or national/federal governments to provide background benefitsbased research on desirable and feasible participation rates.

In terms of Figure 1, the participation-based approach moves beyond facilities/services/ opportunities and considers Outputs 3, use/visits/participation, but stops short of assessing benefits.

\section{Providing (net) benefits}

Planning for the provision of benefits involves basing policies on their efficacy in producing outcomes considered to be desirable by the decision-making body. Benefits are net, in the sense that the benefits should exceed the costs of provision. The benefits of leisure which public policy seeks to secure or enhance are numerous and have been spelled out on a number of occasions (e.g., Driver et al., 1991). In the case of tourism, they are generally seen as the generation of local jobs and incomes. To use leisure benefits as a basis for planning requires some system for assessing, measuring and comparing different bundles of benefits likely to be generated by different policies. Two approaches to the assessment of benefit might be considered: the non-economic Benefits Approach to Leisure ${ }^{4}$, developed by Bev Driver (2008) and his associates in the US Forest Service, and the traditional economics technique of cost-benefit analysis.

\footnotetext{
${ }^{4}$ The approach has been known by a number of names and associated acronyms over the years, the latest being 'Output-Focused Management' (OFM) (Driver (2008), however, one of the earlier names, Benefits Approach to Leisure (BAL) is used here since it seems more distinctive and appropriate in the context of this paper.
} 


\section{Benefits Approach to Leisure}

This approach was developed over a period of about 20 years and essentially seeks to base the planning of new leisure facilities on research evidence about users' assessments of the benefits they receive from visiting different types of existing facility in different settings. As with the Recreation Opportunity Spectrum concept discussed above, this approach was developed within the US Forest Service, so it relates particularly to the management of natural estates, but it has also been promoted as being applicable in wider leisure planning situations. User assessments of benefits are typically based on responses to Likert-type scales related to a wide range of specified benefits, gathered by means of questionnaire-based visitor surveys. The 'benefits' being assessed could also be seen as 'satisfactions'; hence, in Table 1, this type of benefit assessment is labelled 'psychological,' to distinguish it from the economic approach discussed below. Later versions of the system have sought to include stakeholders other than facility users.

The approach is most understandable when applied to enhancement of existing facilities: user assessments of benefits enjoyed, or 'satisfaction scores', are used to decide on appropriate adjustments to management practices, thus resulting, if successful, in higher satisfaction scores. This is in the realm of facility management rather than planning. The one known published account of the application of the approach in an urban context is of this nature (Tucker and Allen, 2008). However, the approach could also provide the basis for some modification to the pattern of supply of facilities - for example, provision of a customdesigned skateboard facility within or near a park complex could result in increased satisfaction scores from both skateboarders previously using unsuitable facilities, and the other users of those facilities who would no longer be inconvenienced by an incompatible activity. Provision of totally new facilities would be more speculative: satisfaction scores from existing facilities with given characteristics would have to be used to estimate likely satisfaction scores for proposed new facilities with similar characteristics. The criterion for making decisions and assessing their success is the level of satisfaction of users at existing and new facilities, as measured by average satisfaction/benefit scores.

As currently promulgated, the approach does not appear to deal with user numbers and costs. It would no doubt be considered desirable to achieve higher user numbers with the same or higher average satisfaction scores, but it is not clear how the desirability of a higher number of users with lower satisfaction scores, or a lower number of users with higher satisfaction scores, would be assessed. Furthermore, consideration of the acceptable level of cost of achieving a given rise in satisfaction level is not intrinsic to the methodology: assessed benefits are gross rather than net. Despite the extensive literature on the development of the system, there are few published examples of its application as a complete planning approach, and even less in urban settings. Furthermore, none of the other guidelines reviewed incorporates the approach. Questions arise as to the practicality of dealing with the more than 200 types of benefit utilised in the system (Driver and Bruns, 2008: 69-73). While early versions of the approach were limited to consideration of benefits as perceived by facility users, later versions have introduced other stakeholders and such features as 'economic benefits' and 'environmental benefits' (Driver and Bruns, 1999), but these additions appear not to have been operationalised. Arguably, it can be said that the approach has yet to be fully operationalised outside the context of public land management in settings such as forest or national park services. 


\section{Cost-benefit analysis}

Cost-benefit analysis has a long history but is frequently misunderstood by non-economists: in particular, it is often thought that the technique considers only the financial aspects of a project, but this is not the case. In a cost-benefit-based planning exercise, decisions are based on estimates of all the identifiable financial, social and environmental costs and benefits which arise throughout the life of a proposed project. Cost-benefit ratios or internal rates of return on capital invested are used to rank proposed projects in order of priority, and projects for which the internal rate of return is lower than the cost of borrowing or servicing the capital involved are not proceeded with. Typically all dis-benefits (costs) and all benefits are identified and, where possible, assigned money values. Any costs or benefits which cannot be measured in this way must be assessed by the decision-makers against the aggregate net costs or net benefits of the items which can be measured. Assessment can extend well beyond the financial matters included in a private sector project assessment. For example, in a costbenefit study of the Adelaide Grand Prix (Burns et al., 1986) a money value was calculated for the dis-benefit of the noise intrusion suffered by some residents and for the 'psychic benefit' of the event to the Adelaide population - that is, the sense of pride and excitement of hosting the event.

One sector where this approach is already used is in the planning of major road investments. Here, national transport agencies fund research to develop generic values for application in local cost-benefit studies, for example the value per hour of travel time (including leisure time) saved and the cost of different types of accident injury (or the value of the benefit of preventing them). This approach is known as 'value transfer' or 'benefit transfer' and could conceivably be developed for leisure planning. Thus, for example, a 1988 study conducted by the Australian government concluded that a physically active person saves the community an average of \$AUST295 a year, in terms of saved health costs and productivity benefits (about \$AUST600 at today's prices). Regularly updated figures of this sort could be used as part of the valuation of benefits arising from some leisure facilities. Moves are being made to achieve this in relation to natural area recreation planning in the United States (Rosenberger and Loomis, 2001) and an exercise has recently been undertaken in New Zealand (Kaval and Yao, 2010). But for such an approach to be widely adopted, research would need to be undertaken to establish a much wider range of values and keep them up-to-date.

While the cost-benefit approach can be a highly technical process to implement from scratch (as opposed to using value transfer), much of this is concerned with the process of identifying and measuring costs and benefits. Ultimately it requires normative decisions to be made by decision-makers in deciding what is or is not a relevant benefit, dis-benefit or cost.

None of the guidelines reviewed recommends the use of cost-benefit analysis as the basis for planning. This may be because of the aforementioned misunderstanding of the technique or because of the level of cost and the skills required to conduct the necessary research, particularly for implementation at the local level. Most of the tourism-related guidelines are, however, based on the goal of increasing economic benefits from tourism in host communities, in the form of increased jobs and incomes. However, rather than a cost-benefit study, these guidelines are, in effect, recommending an economic impact study. Noneconomic costs, such as environmental impacts, are considered separately as constraints, rather than being incorporated into the economic assessment as in cost-benefit analysis. 
In terms of Figure 1, benefits approaches are, by definition, the only approaches which include consideration of Outputs 4, net benefits.

\section{Summary/conclusion}

The following key points can be drawn from the discussion of the eight planning approaches. Fixed provision standards specified by an external authority, of the 'one-size-fits-all' variety, have been widely discredited and beg the question of just how they are derived and what goals are intended to be achieved by the facilities/services prescribed. Seen as a collective term for facilities and services, provision of opportunities is a means to an end, rather than an end in itself and raises the question of the goals to be achieved by the means of facility/ service provision. Managing (natural/heritage) resources is necessarily involved in many leisure planning exercises, as a feature of the input of material resources. Stakeholder consultation is a required part of most planning exercises, and produces a number of types of information, one of which is aspirations regarding desired facilities/services and participation in activities. It seems inevitable, however, that it will be necessary to evaluate the resultant lists of proposals by some additional means such as demand, participation or benefits criteria. Needs-based planning guidelines are generally confused by a lack of definition of need, as either a normative concept ('needs') or a conative disposition ('wants'). Planning only for need in the normative sense is generally not possible because most public leisure facilities and services must inevitably cater to wants as well as needs. Wants and needs taken together are the focus of the demand, participation and benefits approaches. Meeting demand involves the use of simple or complex models, which can estimate likely demand levels under a variety of supply conditions, but setting the supply conditions is precisely what policymaking is required to do, so additional processes are required to determine this. Cost-benefit analysis can aid in this process, by introducing the concept of benefits. Participation target-based planning has the advantage of considering the intended outcomes of the provision of facilities/services/opportunities, namely use/visits/participation, but stops short of considering benefits. Benefits-based planning has the advantage of explicitly considering benefits as the final outcome of the leisure planning and provision process. The non-economic 'Benefits Approach to Leisure' framework has a number of limitations and does not appear to be fully operational outside of public land management settings. The alternative benefit-based approach, cost-benefit analysis, while operationalised, would be prohibitively expensive to implement from scratch in routine local planning exercises, but a value transfer approach, based on nationally funded generic research would be feasible.

This analysis of some 80 sets of planning guidelines points to some sort of demand/ participation/benefits approach to overcome some of the difficulties encountered in a number of the other approaches reviewed. However, determining just how demand modelling, participation target-setting and benefits assessment might be brought together into a locally implementable leisure planning process is a challenge which has not yet been fully faced, at least in the context of this project. 


\section{REFERENCES}

2010 Legacies Now/Creative Cities Network (2007). Cultural planning toolkit. Vancouver, BC: 2010 Legacies Now/Creative Cities Network, available at: www.creativecity.ca.

Alexandris, K. (Ed.) (2008). Special issue: performance measurement and leisure management. Managing Leisure, 13, 3-4).

American Planning Association (2006). Planning and urban design standards. New York: John Wiley.

Australian Social and Recreation Research Pty Ltd (ASR) (2008). Planning for community infrastructure in growth areas. Wyndham, Vic: Wyndham City Council, available at: www.wyndham.vic.gov.au/aboutwyndham/planspolicieslocallaws/commdev/plan cominfr.

Bannon, J. J. (1976). Leisure resources: Its comprehensive planning. Englewood Cliffs, NJ: Prentice Hall.

Baud-Bovy, M., and Lawson, F. (1977). Tourism and Recreation Development. Oxford: Architectural Press.

Baud-Bovy, M., \& Lawson, F. (1998). Tourism and recreation: Handbook of design and planning, $2^{\text {nd }}$ Ed. Oxford: Architectural Press.

BC Recreation and Sport Branch (1980). A guide to recreation planning in British Columbia. Edmonton, British Columbia: Ministry of Provincial Secretary and Government Services.

Berke, P. R., Godschalk, D. R., Kaiser, E. J., \& Rodriguez, D. A. (2006). Urban land use planning. 5th Ed. Urbana/Chicago, IL: University of Illinois Press.

Bernstein, J. S. (2007). Arts marketing insights: The dynamics of building and retaining performing arts audiences. San Francisco, CA: Jossey-Bass.

Birmingham City Council (2007). Birmingham LAA 2008/11: Working together for a better Birmingham. Birmingham City Council, available at: www.bebirmingham.org.uk/ documents/LAA.pdf.

Bradshaw, J. (1972). The concept of social need. New Society, 496, March 30, 640-643.

British Government (2001). A sporting future for all. London: Departments of Culture, Media and Sport, available at: www.culture.gov.uk/Reference_library/Publications/ archive_2000/sporting_future_for_all.htm.

Broadhurst, R. (2001). Managing environments for leisure and recreation. London: Routledge.

Brown, J. (1985). Towards the development of a Commonwealth policy on recreation. Canberra: Department of Sport, Recreation and Tourism.

Buechner, R. D. (Ed.) (1971). National park, recreation and open space standards. Washington, DC: National Park and Recreation Association.

Burns, J. P. A., et al. (Eds) (1986). The Adelaide Grand Prix: The impact of a special event. Adelaide: Centre for South Australian Economics Studies.

Burton, T. L. (1976). Making man's environment: leisure. Toronto: Van Nostrand Reinhold.

Burton, T. L., Ellis, J. B., \& Homenuck, H. P. M. (1977). Guidelines for urban open space planning. Report to the Ministry of State for Urban Affairs, Vanier City, Ont.: Canadian Parks/Recreation Association.

Clark, R., \& Stankey, G. (1979). The Recreation Opportunity Spectrum: a framework for planning, management and research. General Technical Report PNW-98, Seattle, WA: US Dept of Agriculture Forest Service.

Clawson, M., \& Knetsch, J. L. (1966). Economics of outdoor recreation. Johns Hopkins University Press, Baltimore. 
Daly, J. (1995). Recreation and sport planning and design. Adelaide: SA Office of Recreation and Sport.

Daly, J. (2000). Recreation and sport planning and design, $2^{\text {nd }}$ edn. Champaign, IL: Human Kinetics.

Department of Culture, Media and Sport (1999). Local cultural strategies: Draft guidance for local authorities in England. London: DCMS.

Department for Culture, Media and Sport (DCMS)/Strategy Unit (2002). Game plan: A strategy for delivering the government's sport and physical activity objectives. London: Strategy Unit, Cabinet Office.

Department of Communities and Local Government (2010). Councils' data demand overload radically reduced. Media Release, 17 Dec., London: DCLG, available at: www. communities.gov.uk/news/newsroom/1802440.

Department of the Environment (1975). Sport and recreation. Cmnd 6200, London: HMSO.

Department of Environment, Housing and Community Development (1977). Leisure planning guide for local government. Canberra: AGPS.

Department of the Arts, Sport, the Environment, Tourism and Territories (DASETT) (1988). The economic impact of sport and recreation - Regular physical activity. DASETT Technical Paper No. 2, AGPS, Canberra.

Dredge, D., \& Moore, S. (1992). A methodology for the integration of tourism in town planning. Journal of Tourism Studies, 3(1), 8-21.

Dreeszen, C. (1998). Community cultural planning: a guidebook for community leaders. Washington, DC: Americans for the Arts.

Driver, B. L. (Ed.) (2008). Managing to optimize the beneficial outcomes of recreation. State College, PA.: Venture.

Driver, B. L., Brown, P. J., \& Peterson, G. L. (Eds.) (1991). Benefits of leisure. State College, PA: Venture.

Driver, B. L., \& Bruns, D. (2008). Implementing OFM on public nature-based recreation and related amenity resources. In B. L. Driver (Ed.) Managing to Optimize the Beneficial Outcomes of Recreation (pp. 39-73). State College, PA.: Venture.

Elphinstone, R., \& Johnston, C. (1987). Recreation facilities: needs, planning and management. Developments in local government 4. Canberra: AGPS.

Evans, G. (2001). Cultural planning: An urban renaissance? London: Routledge.

Fields in Trust (2008). Planning and design for outdoor sport and play. London: Fields in Trust.

Garrett, T., \& Spedding, A. (1977). Guidelines for community recreation planning. Wellington: Ministry of Recreation.

Godfrey, K., and Clarke, J. (2000). The tourism development handbook. London: Thomson.

Gold, S. M. (1973). Urban recreation planning. Philadelphia: Lea and Febiger.

Grogan, D., \& Mercer, C. (1995). The Cultural Planning Handbook: An Essential Australian Guide. St Leonards, NSW: Allen and Unwin, in association with Arts Queensland and the Australia Council.

Guppy, M. (ed.) (1997). Better places richer communities: cultural planning and local development: a practical guide. Sydney: Australia Council.

Hall, C. M., \& Page, S. J. (2006). The geography of tourism and recreation, $3^{\text {rd }}$ Ed. London: Routledge.

Hamilton-Smith, E. (1975). Issues in the measurement of 'community needs'. Australian Journal of Social Issues, 10(1), 35-45.

Hanley, N., Shaw, W. D., \& Wright, R. E. (Eds.) (2003). The new economics of outdoor recreation. Cheltenham, UK: Edward Elgar. 
Harper, J. (2009). Planning for recreation and parks facilities: Predesign process, principles, and strategies. State College, PA: Venture.

Heritage, Conservation and Recreation Service (1975). The third nationwide outdoor recreation plan: Executive report. US Govt Printing Office, Washington, DC.

House of Lords Select Committee on Sport and Leisure (1973). Second report. London: HMSO.

Inskeep, E. (1991). Tourism planning: An integrated and sustainable development approach. New York: Van Nostrand.

Jackson, P. (1986). Adapting the R.O.S. technique to the urban setting. Australian Parks and Recreation, 22(3), 26-28.

Kaval, P., and Yao, R. (2010). A New Zealand outdoor recreation benefit database for benefit transfer studies. Annals of Leisure Research, 13(4), 709-15.

Kelly, J. R. (1983). Leisure identities and interactions. London: Allen and Unwin.

Kelsey, C., and Gray, H. (1985). Master plan process for parks and recreation. Reston, VA: American Alliance for Health, Physical Education, Recreation and Dance.

Kotler, P., Bowen, J. T., \& Makens, J. C. (2006). Marketing for hospitality and tourism: $4^{\text {th }}$ Ed. Upper Saddle River, NJ: Pearson Education.

Lancaster, R. A. (1983). Recreation, park and open space standards and guidelines. Alexandria, VA: National Park and Recreation Association.

Lord, B. E., \& Elmendorf, W. F. (2008). Are recreation organizations representative of all participants? Journal of Park and Recreation Administration, 26(1), 87-96.

Lothian, A. (1977). A methodology for countryside recreation planning. In D. Mercer (Ed.) Leisure and recreation in Australia, Malvern, Vic.: Sorrett, pp. 141-51.

Marriott, K. (1987). Recreation planning: a manual for local government, $2^{\text {nd }}$ Ed. Adelaide: South Australian Department of Recreation and Sport.

Marriott, K. (1980). Traditional approaches to urban recreation planning. In D. Mercer \& E. Hamilton-Smith (Eds.), Recreation planning and social change (pp. 113-23). Malvern, Vic.: Sorrett,.

Marriott, K. (2010). Planning for the provision of leisure and recreation in Australia. Hobart: Sport \& Recreation Tasmania. Available at: www.development.tas.gov.au/ sportrec/publications_and_links/recreation_planning_manual.

Maslow, A. (1987). Motivation and personality, 3rd Ed.. New York: Longman.

Maw, R. and Cosgrove, D. (1972). Assessment of demand for leisure: A Modelling approach. Working Paper 2/72, London: Built Environment Research Group, Polytechnic of Central London.

McLean, D. D., Bannon, J. J., \& Gray, H. R. (1999). Leisure resources: Its comprehensive planning. Champaign, IL: Sagamore.

Mercer, D. (1973). The concept of recreational need. Journal of Leisure Research, 5(1), 3750.

Mertes, J. D., \& Hall, J. R. (1996). Park, recreation, open space and greenway guidelines. Ashburn, VA: National Recreation and Park Association.

Mill, R. C., and Morrison, A. M. (1985). The tourism system. Englewood Cliffs, NJ: Prentice Hall.

Mill, R. C., and Morrison, A. M. (1998). The tourism system, 3rd Edn. Dubuque, Iowa: Kendall/Hunt.

Mill, R. C., \& Morrison, A. M. (2006). The tourism system, 5th Ed. Dubuque, Iowa: Kendall/Hunt.

Moore, R. L., \& Driver, B. L. (2005). Introduction to outdoor recreation. State College, PA: Venture. 
Murphy, J. F., Niepoth, E. W., Jamieson, L. M., \& Williams, J. G. (1991). Leisure systems:

Critical concepts and applications. Champaign, IL: Sagamore.

Murray, R. D., and Twardzick, L. F. (1970). Planning community-wide recreation. Extension Bulletin e-684, Recreation and Tourism Series. Lansing, MI: Cooperative Extension Service, Michigan State University.

National Capital Development Commission (NCDC) (1976). National capital open space system. Canberra, ACT: NCDC.

National Park Service (1965). Land and water conservation fund State assistance program, Federal Financial Assistance Manual, 69. Washington, DC: National Park Service, available at: www.nature.nps.gov.www.nps.gov/ncrc/programs/lwcf/ plan_prjts.html.

National Playing Fields Association (NPFA) (1971). Outdoor playspace requirements. London: NPFA.

National Playing Fields Association (NPFA) (2001). The six acre standard: minimum standards for outdoor playing space. London: NPFA.

New South Wales (NSW). Department of Arts, Sport and Recreation (2007) Corporate plan: 2007-11. Sydney: DASR.

Nichols, G. (2007). Sport and crime prevention. London: Routledge.

NSW Department of Environment and Planning (NSWDEP) (1984). Guidelines for preparing an open space plan. Sydney: Department of Environment and Planning.

NSW Department of Planning (1992). Outdoor recreation and open place: planning guidelines for local councils. Sydney: Department of Planning.

NSW Dept of Sport \& Recreation (1978). Planning standards for selected sports facilities. Sydney: NSW Dept of Sport \& Recreation, South Coast Region.

NSW Ministry for the Arts/Dept of Local Government (NSWA/DLG) (2004). Cultural planning guidelines. Sydney: Ministry for the Arts/Department of Local Government. Available online: search at: www.dlg. nsw.gov.au/dlg/dlghome/dlg_index.asp

NZ Ministry of Tourism (2004). Tourism planning toolkit for local government. Wellington: Ministry of Tourism, available at: www.tourism.govt.nz/Our-Work/Local-Government/Tourism-Planning-Toolkit/.

Office of the Deputy Prime Minister (1991) Planning policy guidance 17: planning for open space, sport and recreation. London: ODPM.

Office of the Deputy Prime Minister (2002). Planning policy guidance 17: planning for open space, sport and recreation, $2^{\text {nd }}$ Edn. London: ODPM.

Ontario Ministry of Culture and recreation (1976). Guidelines for developing public recreation facility standards. Toronto: Ministry of Culture and Recreation.

Ontario Ministry of Culture and Recreation (1979). Culture and recreation master planning. Toronto, Ontario: Ministry of Culture and Recreation.

Packard, V. (1957). The hidden persuaders. London: Longman.

Paddick, R. J. (1982). The concept of need in planning for recreation. In M. L. Howell \& J. R. Brehaut (Eds), Proceedings of the VII Commonwealth and International Conference on Sport, Physical Education, Recreation and Dance: Vol. 4 (Recreation) (pp. 39-47). Brisbane: Univ. of Queensland.

Page, S. J., \& Connell, J. (2010). Leisure: An introduction. Harlow, Essex: Financial Times Prentice Hall

Palermo, F. (2001). Tourism and community development: An approach. Halifax, NS: Cities and Environment Unit, Dalhousie University.

Pigram, J., \& Jenkins, J. (2006). Outdoor recreation management, $2^{\text {nd }}$ Ed. London: Routledge.

Ravenscroft, N. (1993). Public leisure provision and the good citizen. Leisure Studies, 12(1), 
33-45.

Rosenberger, R. S., \& Loomis, J. B. (2001). Benefit transfer of outdoor recreation use values. Gen. Tech. Rep. RMRS-GTR-72, Fort Collins, CO: US Dept of Agriculture, Forest Service, Rocky Mountain Research Station, available at: www.fs.fed.us/rm/ pubs/rmrs_gtr72.pdf.

Schwarz, L. L.(Ed.)/Conservation Fund (1993). Greenways: a guide to planning, design, and development. Washington, DC: Island Press.

Scottish Sports Council (1996). Facilities planning model. Edinburgh: Scottish Sports Council, available at: www.sportscotland.org.uk.

Shivers, J. S., and Hjelte, G. (1971). Planning recreational places. Cranbury, NJ: Fairleigh Dickinson University Press.

Sport and Recreation Queensland (2003). Open space for sport \& recreation: Planning principles and implementation notes. Brisbane: Sport and Recreation Queensland.

Sport and Recreation Victoria (1990). Community recreation: Municipal recreation planning guide. Melbourne: Sport and Recreation Victoria.

Sport England (2008). Sport England strategy, 2008-2001. London: Sport England, available at: www.sportengland.org/about_us/what_we_do.aspx.

Sport England and Central Council of Physical Recreation (2005). Towards a level playing field: A guide to the production of playing pitch strategies. London: Sport England/ CCPR.

Sports Council (1968). Planning for sport: Report of a working party on scales of provision. London: Central Council of Physical Recreation.

Sports Council, National Playing Fields Association and Central Council of Physical Recreation (1991). Playing pitch strategy. London: Sports Council.

Stankey, G., McCool, S., Clark, R. N., \& Brown, P. J. (1999). Institutional and organizational challenges to managing natural resources for recreation: a social learning model. In E.

L. Jackson and T. L. Burton (Eds.), Leisure studies: Prospects for the Twenty-First Century (pp. 435-450). State College, PA: Venture.

Steiner, F. (1991). Landscape planning: a method applied to a growth management example. Environmental Management, 15(4), 519-29.

Taylor, P. W. (1959). 'Need' statements. Analysis, 19, 106-11.

Taylor, P. (Ed.) (2011). Torkildsen's sport and leisure management, $6^{\text {th }}$ Ed. London: Routledge.

Torkildsen, G. (1983) Leisure and recreation management. London: E\&FN Spon.

Torkildsen, G. (1999). Leisure and recreation management, $4^{\text {th }}$ edn. London: E \& F. N. Spon.

Torkildsen, G. (2005). Leisure and recreation management, $5^{\text {th }}$ Ed. London: Routledge.

Travel and Tourism Administration (TTA)/University of Missouri, Dept of Recreation and Park Administration (1978). Tourism USA: guidelines for tourism development.

Washington, DC : US Department of Commerce, Economic Development

Administration: United States Travel and Tourism Administration.

Travel and Tourism Administration (TTA)/University of Missouri, Dept of Recreation and Park Administration (1991) Tourism USA: Guidelines for Tourism Development, $3^{\text {rd }}$ Edn. Washington, DC : US Department of Commerce, Economic Development Administration: United States Travel and Tourism Administration.

Tucker, T. W., \& Allen, L. R. (2008). Implementing OFM in municipal parks and recreation departments. In B. L. Driver (Ed.), Managing to optimize the beneficial outcomes of recreation (pp. 75-94). State College, PA: Venture.

Urban Research and Development Corporation (1980). Handbook for recreation planning and action: A UPARR action program development guide. Washington, DC: Heritage 
Conservation and Recreation Service.

Vassiliou, G., Manidis Roberts Consultants, Hepper Marriott and Associates, Simon, O., and Van Gulik, S. (1994). Getting it right: a guide to planning and developing sport and recreation facilities. Brisbane: Dept. of Tourism, Sport and Racing and the Hillary Commission (NZ).

Veal, A. J. (2011a). Guidelines for the planning of leisure, sport, tourism and the arts: A review: U-Plan Project Paper 2. On-line publication available at: www.leisuresource. net/service2.aspx

Veal, A. J. (2011b). Leisure and the concept of need: U-Plan Project Paper 4. Available at: www.leisuresource.net/service2.aspx.

Veal, A. J. (2010). Leisure, sport and tourism, politics, policy and planning. Wallingford, UK: CABI.

Veal, A. J. (2006). Economics. In C. Rojek, S .Shaw \& A. J. Veal (Eds.), Handbook of leisure studies (pp. 140-161). London: Palgrave.

Veal, A. J. (2002). Leisure and tourism policy and planning, $2^{\text {nd }}$ Ed. Wallingford, UK: CABI Publishing.

Veal, A. J. (1994) Leisure policy and planning. Harlow, Essex: Longman.

Veal, A. J. (1984). Planning for leisure: Alternative approaches. World Leisure and Recreation, 26(5), 17-24.

Veal, A. J. (1982). Planning for leisure: Alternative approaches. London: Polytechnic of North London.

WA Department of Sport and Recreation (1997). How to...undertake a needs assessment for a sport and recreation facility: A guide for sport and recreation facility planners. Perth: Western Australia Dept of Sport and Recreation.

WA Department of Sport and Recreation (2007). Decision-making guide: Sport and recreation facilities. Perth: Western Australia Department of Sport and Recreation .

Wilkinson, P. F. (1985). The golden fleece: The search for standards. Leisure Studies, 4(2): 189-204.

World Tourism Organization (1993). National and Regional Tourism Planning. London: Routledge.

World Tourism Organization (1998). Guide for Local Authorities on Developing Sustainable Tourism. Madrid: World Tourism Organization. 
Table 1. Summary of guidelines

\begin{tabular}{|c|c|c|c|c|c|c|c|c|c|}
\hline \# & Date & Authors & Country & Pub. type & Edn & Source & Focus & Primary method & Second method \\
\hline 1 & 1965 & Land \& Water Cons. Fund & USA & Report & E1 & Gov & OR & Demand - gross & Stakeholder cons. \\
\hline 2 & 1968 & Sports Council & UK & Report & E1 & Gov & $\mathrm{S}$ & Demand - gross & \\
\hline 3 & 1970 & Murray\& Twardzick & USA & Report & E1 & $\mathrm{Ac}$ & $\mathrm{R}$ & Standards & \\
\hline 4 & 1971 & Shivers and Hjelte & USA & Textbook & E1 & $\mathrm{Ac}$ & $P \& R$ & Standards & \\
\hline 5 & 1971 & Buechner/NRPA & USA & Report & E1 & Prof/Ac & OS \& R & Standards & Demand - gross \\
\hline 6 & 1971 & National Playing Fields Assoc. & UK & Report & E1 of 3 & Ind & PlaySp & Standards & \\
\hline 7 & 1972 & Maw and Cosgrove & UK & WP & E1 & $\mathrm{Ac}$ & $\mathrm{L}$ & Demand - gross & \\
\hline 8 & 1974 & Burton & Can & Book & E1 & $\mathrm{Ac}$ & $\mathrm{L}$ & Need & Participation \\
\hline 9 & 1976 & Bannon & USA & Textbook & E1 of 2 & $\mathrm{Ac}$ & $\mathrm{L}$ & Need & \\
\hline 10 & 1976 & Ontario Min.of Culture \& Rec. & Can & Report & E1 & Gov & $\mathrm{R}$ & Standards & \\
\hline 11 & 1977 & Baud-Bovy \& Lawson PASOLP & Int & Book & E1 of 3 & $\mathrm{Ac}$ & $\mathrm{T}$ & Benefits - econ. & Demand - gross \\
\hline 12 & 1977 & Burton/Ellis/Homenuck & Can & Report & E1 & $\mathrm{Ac}$ & OS & Demand - organic & \\
\hline 13 & 1977 & Dept of Env., Housing etc.. & Aust & Report & E1 & Gov & $\mathrm{L}$ & Stakeholder cons. & Need \\
\hline 14 & 1977 & Garrett \& Spedding & $\mathrm{NZ}$ & Report & E1 & Gov & $\mathrm{R}$ & Demand - organic & Stakeholder cons. \\
\hline 15 & 1977 & Lothian & Aust. & Chapter & E1 & Gov & $\mathrm{CR}$ & Demand - organic & \\
\hline 16 & 1976 & National Capital Dev. Comm. & Aust. & Report & E1 & Gov & OS & Standards & \\
\hline 17 & 1978 & NSW Dept of Sport \& Rec. & Aust & Report & E1 & Gov & $\mathrm{S}$ & Demand - organic & Local standards \\
\hline 18 & 1978 & TTA, USA & USA & Report & E1 of 3 & Ind & $\mathrm{T}$ & Benefits - econ. & Demand - gross \\
\hline 19 & 1979 & Ontario Min.of Culture \& Rec. & Can & Report & E1 & Gov & $\mathrm{R}$ & Demand - gross & Opportunity \\
\hline 20 & 1979 & Clark \& Stankey (ROS) & USA & Report & E1 & Gov & OS & Resource-based & \\
\hline 21 & 1980 & BC Recreation \& Sport Branch & Can. & Report & E1 & Gov & $\mathrm{R} \& \mathrm{~S}$ & Demand - gross & Opportunity \\
\hline 22 & 1980 & Gold & USA & Book & E1 & $\mathrm{Ac}$ & $\mathrm{L}$ & Stakeholder cons. & \\
\hline 23 & 1980 & Urban Res./Dev. Corp. & USA & Report & E1 & Gov & $\mathrm{R}$ & Need & Stakeholder cons. \\
\hline 24 & 1982 & Veal & UK & WP & E1 of 4 & $\mathrm{Ac}$ & $\mathrm{L}$ & Various $^{\star \star}$ & \\
\hline 25 & 1983 & Kelly+C31 & USA & Book & E1 & Ac & L & Need & \\
\hline 26 & 1983 & Lancaster/NRPA & USA & Report & E1 & Prof/Ac & OS & Standards & \\
\hline 27 & 1983 & Torkildsen & UK & Textbook & E1 of 6 & $\mathrm{Ac}$ & $\mathrm{L}$ & Various $^{\star *}$ & \\
\hline 28 & 1984 & NSW Dept Env. Planning & Aust & Report & E1 & Gov & OS & Need & \\
\hline 29 & 1985 & Kelsey \& Gray & USA & Report & E1 & Prof/Ac & $\mathrm{R}$ & Demand - gross & Standards \\
\hline 30 & 1985 & Mill \& Morrison & USA & Textbook & E1 of 5 & $\mathrm{Ac}$ & $\mathrm{T}$ & Benefits - econ. & Demand - gross \\
\hline 31 & 1984 & NSW Dept Env./Planning & Aust & Report & E1 & Gov & OS & Need & \\
\hline
\end{tabular}




\begin{tabular}{|c|c|c|c|c|c|c|c|c|c|}
\hline 32 & 1987 & Elphinstone \& Johnston & Aust. & Report & E1 & Gov/Cnslt & $\mathrm{R}$ & Need & Standards \\
\hline 33 & 1987 & Marriott/SA & Aust & Report & E1 & Gov/Cnslt & $\mathrm{L}$ & Stakeholder cons. & Opportunity \\
\hline 34 & 1990 & Sport \& Recreation Vic. & Aust & Report & E1 & Gov & $\mathrm{R}$ & Stakeholder cons. & Need \\
\hline 35 & 1991 & Driver et al. & USA & Report & E1 & $\mathrm{Ac}$ & $\mathrm{L}$ & Benefits - psych & \\
\hline 36 & 1991 & Inskeep & USA & Book & E1 & Ind/Ac & $\mathrm{T}$ & Benefits - econ. & Demand \\
\hline 37 & 1991 & Office of the Deputy PM & UK & Report & E1 of 2 & Gov & $\mathrm{L}$ & Need & \\
\hline 38 & 1991 & TTA, USA & USA & Report & E3 of 3 & Gov/Ac & $\mathrm{T}$ & Benefits - econ. & \\
\hline 39 & 1991 & Sports Council/NPFA/CCPR & UK & Report & E1 of 2 & Gov/Vol. & $\mathrm{S}$ & Demand - gross & \\
\hline 40 & 1991 & Steiner & USA & Article & E1 & $\mathrm{Ac}$ & OS & Resource-based & Stakeholder cons. \\
\hline 41 & 1992 & NSW DoP/Manidis Roberts & Aust & Report & E1 & Gov/Cnslt & OS & Stakeholder cons. & \\
\hline 42 & 1992 & Dredge \& Moore & Aust & Article & E1 & $\mathrm{Ac}$ & $\mathrm{T}$ & Demand - gross & \\
\hline 43 & 1993 & Schwarz/Conservation Fund & USA & Report & E1 & Vol/Cnslt & OS & Resource-based & \\
\hline 44 & 1993 & Hillary Commission & $\mathrm{NZ}$ & Report & E1 & Gov/Cnslt & $\mathrm{R}$ & Stakeholder cons. & \\
\hline 45 & 1993 & WTO/McIntyre & Int & Report & E1 of 2 & Ind/Ac & $\mathrm{T}$ & Benefits - econ. & \\
\hline 46 & 1994 & Veal & UK/Aust & Textbook & E1 of 4 & $\mathrm{Ac}$ & $\mathrm{L}$ & Various ${ }^{\star *}$ & \\
\hline 47 & 1995 & Daly & Aust & Report & E1 of 2 & Ac & $\mathrm{R} \& \mathrm{~S}$ & Benefits & \\
\hline 48 & 1995 & Grogan \& Mercer/Aust. Council & Aust & Book & E1 & Gov/Ac & $\mathrm{C}$ & Stakeholder cons. & \\
\hline 49 & 1996 & Mertes \& Hall/NRPA & USA & Report & E1 & Prof/Ac & $P \& R$ & Demand - organic & \\
\hline 50 & 1996 & Scottish Sports Council & UK & Report & E1 & Gov & $\mathrm{S}$ & Demand - gross & \\
\hline 51 & 1997 & Guppy/Australia Council & Aust & Report & E1 & Gov/Cnslt & $\mathrm{C}$ & Need & \\
\hline 52 & 1997 & WA Dept of Sport \& Rec & Aust & Report & E1 & Gov & $\mathrm{S}$ & Need & \\
\hline 53 & 1998 & Baud-Bovy PASOLP & Int & Report & E3 of 3 & $\mathrm{Ac}$ & $\mathrm{T}$ & Demand - gross & \\
\hline 54 & 1998 & Dreeszen/Americans for the Arts & USA & Report & E1 & Ind/Ac & $\mathrm{C}$ & Stakeholder cons. & \\
\hline 55 & 1998 & WTO/Inskeep & Int & Book & E2 of 2 & Ind/Ac & $\mathrm{T}$ & Benefits - econ. & Demand \\
\hline 56 & 1998 & Mill \& Morrison & USA & Textbook & E3 of 5 & $\mathrm{Ac}$ & $\mathrm{T}$ & Benefits - econ. & Demand - gross \\
\hline 57 & 1999 & Bannon et al. & USA & Textbook & E2 of 2 & Ac & L & Need & \\
\hline 58 & 1999 & Dept Culture/Media/Sport & UK & Report & E1 & Gov & $\mathrm{L}$ & Stakeholder cons. & Need \\
\hline 59 & 1999 & Torkildsen & UK & Textbook & E4 of 6 & Ac & L & Various** & \\
\hline 60 & 2000 & Daly & Aust & Book & E2 of 2 & $\mathrm{Ac}$ & $\mathrm{R} \& \mathrm{~S}$ & Benefits & \\
\hline 61 & 2000 & Godfrey \& Clarke & UK & Book & E1 & $\mathrm{Ac}$ & $\mathrm{T}$ & Benefits - econ. & \\
\hline 62 & 2001 & Evans & UK & Book & E1 & Ac & C & Stakeholder cons. & \\
\hline 63 & 2001 & National Playing Fields Assoc. & UK & Report & E2 of 3 & Ind & PlaySp & Standards & \\
\hline 64 & 2001 & Palermo & Brazil/Can. & Report & E1 & Ac & $\mathrm{T}$ & Resource-based & Demand \\
\hline
\end{tabular}




\begin{tabular}{|c|c|c|c|c|c|c|c|c|c|}
\hline 65 & 2002 & Office of the Deputy PM & UK & Report & E2 of 2 & Gov & $\mathrm{L}$ & Need & \\
\hline 66 & 2002 & Veal & UK/Aust & Textbook & E3 of 4 & Ac & $\mathrm{L}$ & Various** & \\
\hline 67 & 2003 & Sport \& Recreation Qld & Aust. & Report & E1 & Gov & OS & Standards & \\
\hline 68 & 2003 & NSW Arts \& Dept. Local Gov & Aust & Report & E1 & Gov & $\mathrm{C}$ & Stakeholder cons. & \\
\hline 69 & 2004 & NZ Ministry of Tourism & NZ & Report & E1 & Gov/Ac & $\mathrm{T}$ & Benefits - econ. & \\
\hline 70 & 2005 & Sport England/CCPR & UK & Report & E1 & Gov/Ind & $\mathrm{S}$ & Demand - gross & \\
\hline 71 & 2006 & American Planning Assoc. & USA & Report & E1 & Prof & OS & Demand - organic & \\
\hline 72 & 2006 & Berke et al. & USA & Textbook & E5 & $\mathrm{Ac}$ & $\mathrm{R} \& \mathrm{OS}$ & Standards & \\
\hline 73 & 2006 & Mill \& Morrison & USA & Textbook & E5 of 5 & $\mathrm{Ac}$ & $T$ & Benefits - econ. & Demand - gross \\
\hline 74 & 2007 & 2010 Legacies Now etc. & USA & Report & E1 & Ind & C & Stakeholder cons. & \\
\hline 75 & 2007 & WA Dept of Sport \& Rec & Aust. & Report & E1 & Gov & $S \& R$ & Demand - organic & Various \\
\hline 76 & 2008 & Aust. Social \& Rec. Research & Aust. & Report & E1 & Gov/Cnslt & $S \& R$ & Standards & \\
\hline 77 & 2008 & Fields in Trust (formerly NPFA) & UK & Report & E3 of 3 & Ind & PlaySp & Standards & \\
\hline 78 & 2009 & Harper & USA & Book & E1 & $\mathrm{Ac}$ & S\&R & Various** & \\
\hline 79 & 2010 & Marriott/Tasmania & Aust. & Report & E1 & Gov/Cnslt & $L \& R$ & Stakeholder cons. & Demand - gross \\
\hline 80 & 2010 & NSW Dept planning & & & & & & & \\
\hline 81 & 2010 & Veal & Aust. & Textbook & E4 of 4 & $\mathrm{Ac}$ & $\mathrm{L}, \mathrm{S} \& \mathrm{~T}$ & Participation & \\
\hline 82 & 2011 & Taylor/Torkildsen & UK & Textbook & E6 of 6 & Ac & $L \& S$ & Various** & \\
\hline
\end{tabular}

Notes

A copy of this list is available on-line at www.leisuresource.net/service2.aspx. It will be updated from time to time: comments to Tony.Veal@uts.edu.au Source

Ac $=$ Academic

Cnslt = Consultants

Gov = Government $\&$ government agencies/quangos

Ind = Industry

Prof $=$ Professional body

Vol = Voluntary/charitable body

\section{Focus}

$A=$ Arts

$\mathrm{C}=$ Culture

$\mathrm{L}=$ Leisure

OR $=$ Outdoor recreation

OS = Open space
$\mathrm{P}=$ Parks

PlaySp = Play space

$\mathrm{R}=$ Recreation

$\mathrm{S}=$ Sport

$\mathrm{T}=$ Tourism

Yes $^{*}=$ analysis method is implicit in the use of standards, although, typically, little detail is provided.

** Textbooks by Veal, Torkildsen and Harper include a number of specific alternative techniques/approaches. Since there is no main approach, in

Tables 1 and 2 the planning approach is indicated as 'Various'. Details are provided in the table below. 
Table 1a. Veal, Torkildsen and Harper: details of planning techniques/approaches .

\begin{tabular}{|c|c|c|c|c|c|c|c|c|}
\hline & \multicolumn{4}{|l|}{ Veal } & \multicolumn{3}{|c|}{ Torkildsen } & \multirow[t]{2}{*}{ Harper } \\
\hline & E1 & E2 & E3 & E4 & E1 & E4 & E6 & \\
\hline Community development & $\$$ & $\$$ & $\$$ & $\$$ & & & & \\
\hline Demand - gross & $\$$ & $\$$ & $\$$ & & & $\$$ & $\$$ & $\$$ \\
\hline Grid/matrix & $\$$ & $\$$ & $\$$ & & & & & \\
\hline Hierarchies & $\$$ & $\$$ & $\$$ & & & $\$$ & $\$$ & \\
\hline Importance-performance & & & $\$$ & $\$$ & & & & $\$$ \\
\hline Issues & $\$$ & $\$$ & $\$$ & $\$$ & & & & $\$$ \\
\hline Needs-based* & & & & & $\$$ & $\$$ & $\$$ & \\
\hline Organic/incremental & $\$$ & $\$$ & $\$$ & & & & & \\
\hline Participation-based & & & & $\$$ & & & & \\
\hline Priority social area analysis* & & $\$$ & $\$$ & & & & & \\
\hline Resource-based /ROS & & & & & & & & \\
\hline Stakeholder consultation & & & & $\#$ & & $\$$ & $\$$ & $\$$ \\
\hline Spatial & $\$$ & $\$$ & $\$$ & $\$$ & & $\$$ & $\$$ & \\
\hline Standards & 11 & 11 & " & 11 & $\$$ & $\$$ & 11 & $\$$ \\
\hline
\end{tabular}

* Confusingly, Torkildsen dealt with aspects of these approaches under two headings: 'matrix/grid approach' and 'need index approach', and in E6 the latter was renamed 'Social area/need index'

$\$=$ included as possible method to use

$"$ = critiqued

\# = included as component of planning 